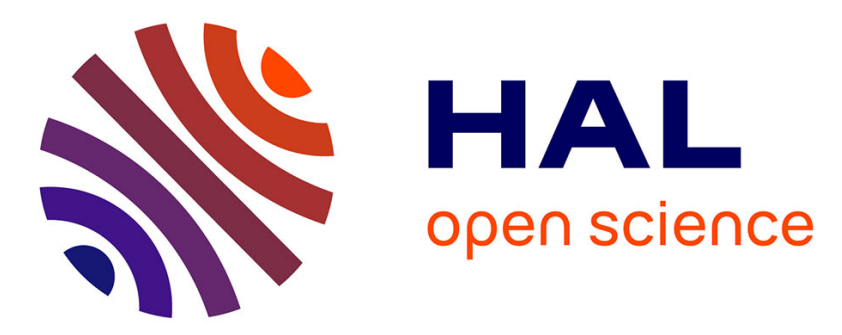

\title{
Sensitive liposomes encoded with oligonucleotide amphiphiles: a biocompatible switch
}

Arnaud Gissot, Carmelo Di Primo, Isabelle Bestel, Gregory Giannone, Hubert Chapuis, Philippe Barthélémy

\section{- To cite this version:}

Arnaud Gissot, Carmelo Di Primo, Isabelle Bestel, Gregory Giannone, Hubert Chapuis, et al.. Sensitive liposomes encoded with oligonucleotide amphiphiles: a biocompatible switch. Chemical Communications, 2008, 43, pp.5550-5552. 10.1039/B812398E . hal-02484276

\section{HAL Id: hal-02484276 \\ https://hal.science/hal-02484276}

Submitted on 19 Feb 2020

HAL is a multi-disciplinary open access archive for the deposit and dissemination of scientific research documents, whether they are published or not. The documents may come from teaching and research institutions in France or abroad, or from public or private research centers.
L'archive ouverte pluridisciplinaire HAL, est destinée au dépôt et à la diffusion de documents scientifiques de niveau recherche, publiés ou non, émanant des établissements d'enseignement et de recherche français ou étrangers, des laboratoires publics ou privés. 


\title{
Sensitive liposomes encoded with oligonucleotide amphiphiles: a biocompatible switch
}

\author{
Arnaud Gissot, Carmelo Di Primo, Isabelle Bestel, Gregory Giannone, Hubert Chapuis and Philippe \\ Barthélémy*
}

Life and oligonucleotides (DNA and RNA) are intimately intertwined. These somewhat chemically simple natural polymers indeed feature virtually infinite and programmable molecular recognition possibilities with exquisite specificity. Hence, many oligonucleotide-based supramolecular systems have been successfully used in biotechnology. ${ }^{[1]}$ Most of these applications require the oligonucleotides $(\mathrm{ON})$ to be bound to a support either solid (gold, glass or silicon e.g. in DNA chips) or fluid (lipid membranes). In the latter case, a lipophilic motif must somehow be tethered to the $\mathrm{ON}$ - in general covalently - to yield an oligonucleotide amphiphile (ONA) that is capable of binding to lipid bilayers. Supramolecular systems based on ONA have attracted considerable attention ${ }^{[2,3]}$ owing to their biocompatibility, capability of molecular recognition ${ }^{[4]}$ even at the single base level, ${ }^{[5]}$ e.g. in sandwich hybridization assays, ${ }^{[6]}$ cell biology, ${ }^{[2]}$ and medicine. ${ }^{[7]}$ These applications rely on the ability of the ONA to recognize and bind specific single-stranded ON targets at the lipid/water interface. Of particular interest is the design of encoded supramolecular systems that can undergo a transformation under the control of a physical or chemical stimulus. Despite the diversity of molecular switches reported so $f a r,{ }^{[8]}$ it remains a challenge to develop a biocompatible model that can operate and be triggered under physiological conditions. Herein, we show that DNA-tagged liposomes (made of DOPC) specifically bind to a fluorescently labeled complementary DNA with no or little influence from the lipid bilayer. Depending on an external stimulus, either physical (temperature) or chemical (competitive complementary ON), the liposome switch between an on and off state depending on the location of the probe at the surface or in the bulk (Scheme 1).

[*] Dr. A. Gissot, Dr. I. Bestel, Dr. H. Chapuis, Prof. P. Barthélémy

Université de Bordeaux, INSERM U869

146 rue Léo Saignat, 33076 Bordeaux (France)

Fax: (+33) 557571015

E-mail: philippe.barthelemy@inserm.fr

Homepage: http://www.iecb.u-bordeaux.fr/arna_u869/

Dr. C. Di Primo

IECB, INSERM U869

2 rue Robert Escarpit, 33607 Pessac (France)

Dr. G. Giannone

CNRS UMR 5091 PCS, Institut F. Magendie

146 rue Léo Saignat, 33077 Bordeaux (France)

[**] P.B. and H.C. acknowledge financial support from the Army Research Office.

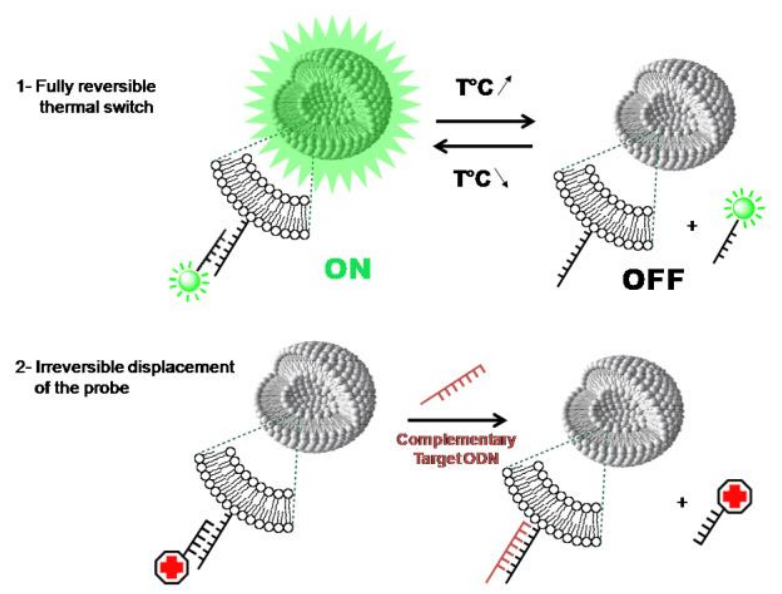

Scheme 1. Illustrative sketch of 1) the thermo-controlled reversible switch and 2) the chemical irreversible switch. Below the $T_{m}$ of the duplex, the probe is centered onto the liposome surface (on state). When increasing the temperature above $T_{m}$ (or in the presence of a complementary $\mathrm{ON}$ ), the fluorescent probe is expelled from the surface (off state)

The DOPC multilamellar liposomes were prepared using the freeze/thaw method (see SI). For this proof of principle investigation the sequence of the ON chain of the ONA was optimized (Hyther ${ }^{\mathrm{TM}}$, http://ozone3.chem.wayne.edu/) to (1) avoid self-complementary strands and (2) obtain a melting temperature $\left(\mathrm{T}_{\mathrm{m}}\right)$ of $37^{\circ} \mathrm{C}$ for a $14-$ mer DNA duplex in the presence of $100 \mathrm{mM}$ monovalent cation. Membrane anchor was brought about by the di-C $\mathrm{C}_{15}$ ketal motif. It was expected to provide sufficient hydrophobic driving force for stable insertion of the ONA into bilayers ${ }^{[9]}$ while avoiding too strong self-association. ${ }^{[10]}$ Besides, given the zwiterrionic phosphocholine polar head of DOPC at the liposome surface, ${ }^{[11,12]}$ and for atom economy reasons, no spacer was inserted in between the ON headgroup and the hydrophobic tail. The two complementary ONA and $\mathbf{O N A _ { 2 }}$ were then synthesized along with the control DNA $\mathbf{A}_{1}$ and $\mathbf{A}_{2}$ that lack the hydrophobic motif (Figure 1). The synthesis of $\mathbf{O N A}_{1}$ and $\mathbf{O N A}_{2}$ is straightforward using classical phosphoramidite chemistry (see SI). Note that due to the chemical synthesis of DNA in the 3'-5' direction, the phosphoramidite $\mathbf{1}$ used for the preparation of ONA is attached in a head to head (5'-5') fashion when incorporated last onto the solid support. 


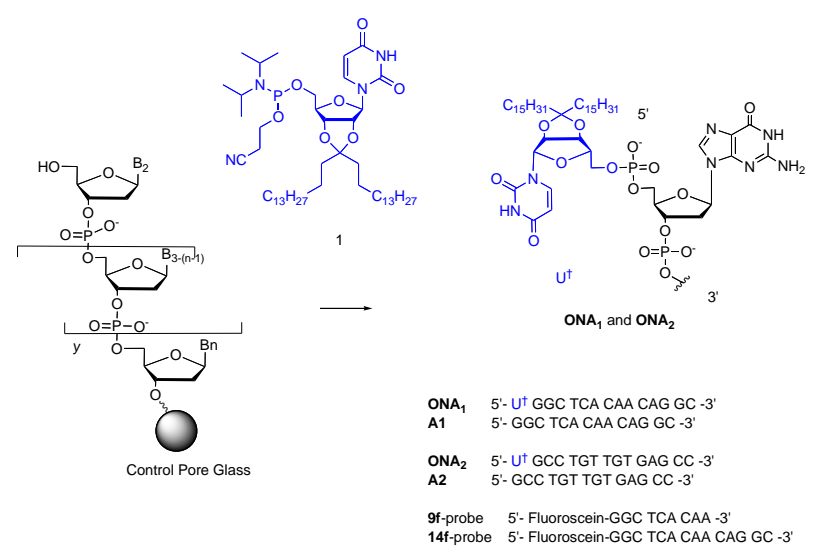

Figure 1. Chemical structures of $O \mathrm{NA}_{1}$ and $O \mathrm{ONA}_{2}$, control DNA $\mathbf{A}_{1}$ and $\mathbf{A}_{2}, \mathbf{9}$ - and 14-mer fluorescein DNA probes (9f and $\mathbf{1 4 f}$ respectively).

Duplex formation between a DNA and a complementary ONA present at the surface of a liposome has been first visualized by Shohda. ${ }^{[12]}$ DNA recognition principles on the surface of liposomes have also been utilized to induce liposome fusion. ${ }^{[13]}$ Yet, the behavior of flexible macromolecules attached to lipid bilayers ${ }^{[14]}$ is greatly influenced by the surface (lipidic or other). Despite its significance in biotechnology, the influence of the lipid membrane on the thermodynamics and kinetics of ON duplex formation has received little attention. Bunge and coll. have thoroughly investigated the thermodynamics thereof, ${ }^{[15]}$ no kinetic data being available to our knowledge. Successful implementation of our ONA-based platform as molecular logical gates requires DNA pairing at the surface of the liposome to be at least as fast and accurate as in the bulk. Surface plasmon resonance (SPR) was used to compare hybridization kinetics of unmodified duplexes with related complexes formed between $\mathbf{O N A _ { 2 }}$ embedded into the liposome surface and fully or partially complementary ON (modified or not with fluorescein, see Figure 1). Although performed at a solid-liquid interface, the kinetic and thermodynamic parameters obtained with this surface-based technique usually match those in solution. ${ }^{[16]}$ A streptavidin-coated surface was used to immobilize the unmodified target $\mathbf{A}_{2}$. A surface, referred to as L1, consisting in a carboxymethylated hydrogel with covalently attached lipophilic groups was used to capture the liposomes with embedded ONA2. ${ }^{[17]}$ In addition a stable baseline was observed after this capture indicating a stable insertion of ONA2 into the bilayer: no equilibrium exists with free or self-assembled aggregates of ONA ${ }_{2}{ }^{[10]}$ Sensorgrams - obtained by the kinetic titration methodfor $\mathbf{O N A}_{\mathbf{2}}$ and $\mathbf{A}_{\mathbf{2}}$ binding to $\mathbf{9 f}$ and $\mathbf{1 4 f}$ are shown in Figure 2 (see SI Figure Sup2 for binding to 9 and 14).
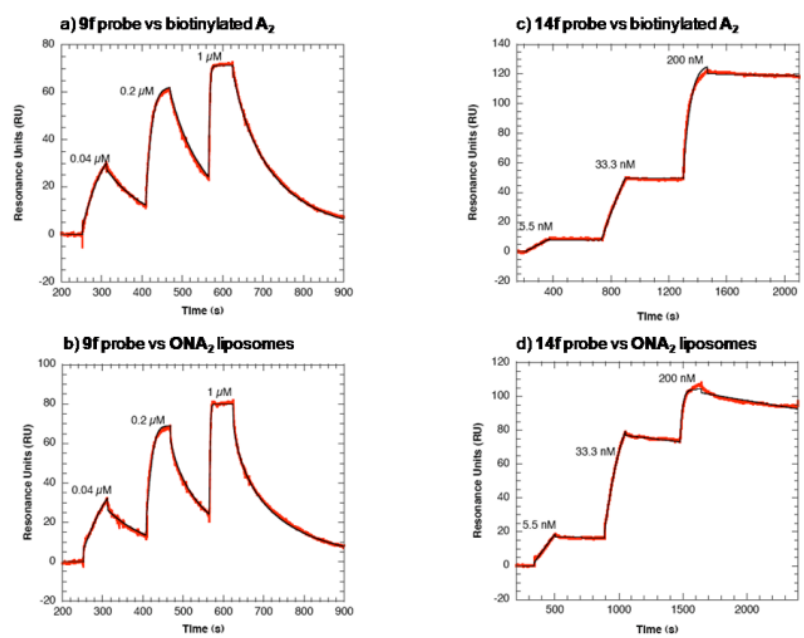

Figure 2. Kinetic analysis of DNA duplex formation. Iterative injections of $9 f(0.04 \mu \mathrm{M}, 0.2 \mu \mathrm{M}$ and $1 \mu \mathrm{M})$ across a) $\mathbf{A}_{2}$ - and b) $\mathrm{ONA}_{2}$-coated chip. Iterative injections of $14 \mathrm{f}(5.5 \mathrm{nM}, 33.3 \mathrm{nM}$ and $200 \mathrm{nM}$ ) across c) $\mathbf{A}_{2}$ - and d) $\mathbf{O N A}_{2}$-coated chip. The sensorgrams were fitted (black curves) as described in the SI.

In both cases the sensorgrams were fitted assuming a one step reaction. The kinetic constants and the apparent equilibrium dissociation constants for each complex determined from direct curve fitting of the sensorgrams are listed in Table 1.

Table 1 (double column, see below)

The fluorescent probe has no effect on the stable 14- $\mathbf{A}_{\mathbf{2}}$ duplex $\left(\mathrm{K}_{\mathrm{d}}=\right.$ $0.28 \mathrm{nM}$ ) while it slightly increases the stability of the $\mathbf{9}-\mathbf{A}_{\mathbf{2}}$ one by decreasing the off rate. This likely results from a favorable stacking of the probe on top of the shorter helix. Overall, the absolute values of the kinetic parameters obtained with 9 or 14 nt ligands and ONA2 loaded liposomes captured on the L1 sensorchip are similar compared to the unmodified $\mathbf{A}_{2}$-coated surface. A 14 nt scrambled sequence injected up to $1 \mu \mathrm{M}$ did not interact either with $\mathbf{A}_{2}$ or ONA2 (see SI, Figure Sup3). No aspecific binding of ON onto the liposome takes place and the association between ONA 2 and its complementary $\mathrm{ON}$ is very likely mediated by specific WatsonCrick base pairing. The results clearly demonstrate that an ONA embedded into the liposome surface behaves as an unmodified DNA strand for recognizing complementary sequences. In particular and despite the absence of spacer, the zwiterrionic lipid membrane has virtually no effect on DNA duplex annealing and fusion even with 14 or $14 f$ complementary DNA whose 3'-ends lye in the Debye layer of the liposome. Furthermore, our results indicate that fusion of DNA duplexes onto DOPC liposomes is unaffected and can be used to develop our DNA-tagged liposomes platform for detection and delivery.

Our thermal switch concept-based on our DNA-tagged liposomes-relies on the thermo-controlled localization of fluorescence at the surface of liposomes. Below a threshold temperature, the fluorescence is concentrated at the surface of the liposomes and the system is on. Above that temperature, the fluorescence is expelled from the surface giving the off state. At the molecular level, the reversible switch is triggered by the annealing/melting of the 9f-ONA2 DNA duplex (Scheme 1). Several limitations in our design are obvious: the melting temperature $\left(\mathrm{T}_{\mathrm{m}}\right)$ of the duplex must be (1) above room temperature to observe the thermal switch and (2) low enough to preserve the integrity of the liposome suspension and thus ensure reversibility. Nevertheless, $\mathrm{T}_{\mathrm{m}}$ are experimentally finely tuned over a wide range of temperatures 
simply by optimizing the length of the duplex and/or the ionic strength of the medium. First attempts to UV-monitor the melting of the duplex at the surface of the liposomes proved impossible (results not shown), most probably because the colloid scatters light. In contrast, the $\mathrm{T}_{\mathrm{m}}$ of the different duplexes were easily monitored in the absence of DOPC (see SI Figure Sup1). We found a $T_{m}$ of ca. $28^{\circ} \mathrm{C}$ for the 9f-ONA2 duplex in phosphate buffer $40 \mathrm{mM} \mathrm{pH} 6.6$ without added salts. ${ }^{[18]}$ In practice, such a $\mathrm{T}_{\mathrm{m}}$ for the 9f-ONA duplex appeared ideal as it abides by the two rules mentioned above.

Liposomes loaded with ONA2 were then incubated with the 9f probe at ca. $20^{\circ} \mathrm{C}$ and the thermal switch investigated by epifluorescence microscopy. The switch proved fully operative and quite satisfyingly fully reversible (see moviel in SI). Hence, the fluorescence is localized at the liposome surface below the $\mathrm{T}_{\mathrm{m}}$ of the 9f-ONA2 duplex and the liposomes are switched off at higher temperatures. The reversibility of the switch was checked 4 times back and forth without any noticeable changes in the appearance of the suspension. Interestingly and in line with SPR experiments, the $\mathrm{T}_{\mathrm{m}}$ of the 9f-ONA 2 duplex seems to be virtually unaffected when present at the surface of the liposome. The whole process is thus being driven by specific Watson-Crick base pairing at the surface of the liposome. Hence, the fully complementary $14 \mathrm{f}$ fluorescent probe (14f-ONA $\mathrm{O}_{2}$ duplex $\mathrm{T}_{\mathrm{m}}>50^{\circ} \mathrm{C}$ ) remains localized onto the surface throughout the temperature interval tested $\left(19-41^{\circ} \mathrm{C}\right.$ ) (see movie2 in SI).

Finally, liposomes are irreversibly switched off by addition of a 14mer DNA complementary either to the fluorescent $\mathbf{1 4 f}$ probe or ONA2 (see movie3 in SI) while a scramble 14-mer DNA complementary to $\mathbf{O N A}_{2}$ has no effect even after melting of the 14fONA2 duplex (not shown).

In summary, this paper reports the synthesis and physicochemical properties of ONA inserted into DOPC liposomes. Interestingly DNA recognition principles, thermodynamics and kinetics are unaffected at the liposome surface. Based on this simple sensitive platform, several applications have been demonstrated: (1) a thermo-responsive fully reversible molecular switch and (2) a potential delivery vehicle for biologically active molecules. In fact, provided a drug is tethered to the ON complementary to the ONA, the drug release could be triggered either by a competitive RNA or DNA (or proteins if the ONA features an aptameric ON) present in the targeted organs or by temperature. The latter approach could be advantageously applied in combination with ultrasound thermotherapy to release a molecule of interest in a egio-controlled manner. ${ }^{[19]}$ Interestingly, the temperature of release could be finely tuned simply by adjust the sequence of the ON tag.

[1] a) I. W. Hamley, V. Castelletto, Angew. Chem. Int. Ed. 2007, 46, 4442-4455; b) S. Pitchiaya, Y. Krishnan, Chem. Soc. Rev. 2006, 35 , 1111-1121.

[2] A. Gissot, M. Camplo, M. W. Grinstaff, P. Barthelemy, Org. Biomol. Chem. 2008, 6, 1324-1333.

[3] H. Rosemeyer, Chem. Biodiversity 2005, 2, 977-1062.

[4] a) F. Patolsky, A. Lichtenstein, I. Willner, J. Am. Chem. Soc. 2001, 123, 5194-5205; b) F. Patolsky, A. Lichtenstein, I. Willner, Angew. Chem. Int. Ed. 2000, 39, 940-943.

[5] M. Banchelli, D. Berti, P. Baglioni, Angew. Chem. Int. Ed. 2007, 46, 3070-3073.

[6] a) K. Edwards, A. Baeumner, Anal. Bioanal. Chem. 2006, 386, 16131623; b) G. S. Rule, R. A. Montagna, R. A. Durst, Anal. Biochem. 1997, 244, 260-269.

[7] E. Forssen, M. Willis, Adv. Drug Delivery Rev. 1998, 29, 249-271.

[8] C. P. Mountford, A. H. Buck, C. J. Campbell, P. Dickinson, E. E. Ferapontova, J. G. Terry, J. S. Beattie, A. J. Walton, P. Ghazal, A. R. Mount, J. Crain, J. Phys. Chem. B 2008, 112, 2439-2444.

[9] I. Pfeiffer, F. Hook, Anal. Chem. 2006, 78, 7493-7498; I. Pfeiffer, F. Hook, J. Am. Chem. Soc. 2004, 126, 10224-10225.

[10] C. Gosse, A. Boutorine, I. Aujard, M. Chami, A. Kononov, E. CogneLaage, J. F. Allemand, J. Li, L. Jullien, J. Phys. Chem. B 2004, 108, 6485-6497.

[11] B. F. Marques, J. W. Schneider, Langmuir 2005, 21, 2488-2494.

[12] K. Shohda, T. Toyota, T. Yomo, T. Sugawara, ChemBioChem 2003, 4, 778-781.

[13] G. Stengel, R. Zahn, F. Hook, J. Am. Chem. Soc. 2007, 129, 95849585 .

[14] C. Tribet, F. Vial, Soft Matter 2008, 4, 68-81.

[15] A. Bunge, A. Kurz, A. K. Windeck, T. Korte, W. Flasche, J. Liebscher, A. Herrmann, D. Huster, Langmuir 2007, 23, 4455-4464.

[16] a) Y. S. Day, C. L. Baird, R. L. Rich, D. G. Myszka, Protein Sci. 2002, 11, 1017-1025; b) F. Duconge, C. Di Primo, J. J. Toulme, J. Biol. Chem. 2000, 275, 21287-21294.

[17] C. L. Baird, E. S. Courtenay, D. G. Myszka, Anal. Biochem. 2002, 310, 93-99.

[18] Of note the presence of the hydrophobic motif had little influence on

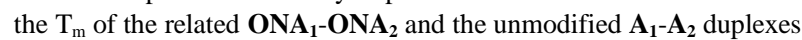

[19] R. Deckers, C. Rome, C. T. Moonen, J. Magn. Reson. Imaging 2008, 27, 400-409.

Table 1. Kinetic parameters $\left(\mathrm{k}_{\mathrm{on}}\right.$ and $\left.\mathrm{k}_{\mathrm{off}}\right)$ and apparent dissociation constants $\left(\mathrm{K}_{\mathrm{d}}\right)$ for complexes formed between DNA sequences and $\mathbf{A}_{2}$, or ONA2.

\begin{tabular}{|c|c|c|c|c|c|c|}
\hline \multirow{3}{*}{ DNA sequence } & $\mathrm{k}_{\mathrm{on}}$ & $\mathrm{k}_{\text {off }}$ & $\mathrm{K}_{\mathrm{d}}$ & $\mathrm{k}_{\text {on }}$ & $\mathrm{k}_{\text {off }}$ & $\mathrm{K}_{\mathrm{d}}$ \\
\hline & \multicolumn{3}{|c|}{ Complexed with $\mathbf{A}_{2}$} & \multicolumn{3}{|c|}{ Complexed with $\mathbf{O N A}_{2}$} \\
\hline & $X 10^{5} M^{-1} s^{-1}$ & $X 10^{-5} \mathrm{~s}^{-1}$ & $\mathrm{nM}$ & $\mathrm{X} 10^{5} \mathrm{M}^{-1} \mathrm{~s}^{-1}$ & $X 10^{-5} \mathrm{~s}^{-1}$ & $\mathrm{nM}$ \\
\hline 5'-GGCTCACAA-3' (9) & $4.9 \pm 0.8$ & $2936 \pm 298$ & $59.6 \pm 3.9$ & $6.8 \pm 2.2$ & $3230 \pm 886$ & $48.9 \pm 13.2$ \\
\hline 5' F-GGCTCACAA-3' (9f) & $5.1 \pm 0.7$ & $1273 \pm 76$ & $25.4 \pm 3.9$ & $6.7 \pm 2.6$ & $1877 \pm 367$ & $31.2 \pm 12.6$ \\
\hline 5'-GGCTCACAACAGGC-3' (14) & $1.8 \pm 0.4$ & $4.4 \pm 2.6$ & $0.25 \pm 0.12$ & $3.8 \pm 0.2$ & $16.3 \pm 4.3$ & $0.43 \pm 0.10$ \\
\hline 5' F-GGCTCACAACAGGC-3' (14f) & $1.7 \pm 0.9$ & $4.2 \pm 2.9$ & $0.28 \pm 0.18$ & $3 \pm 1$ & $14.6 \pm 6.6$ & $0.49 \pm 0.10$ \\
\hline
\end{tabular}

$\mathrm{k}_{\mathrm{on}}, \mathrm{k}_{\mathrm{off}}$ and $\mathrm{K}_{\mathrm{d}}$ are the means and standard deviations of at least 3 independent experiments. F=fluoroscein 